\title{
Treating allergic rhinitis by sublingual immunotherapy: a review
}

\author{
Cristoforo Incorvaia (a), Alessia Di Rienzo ${ }^{(b)}$, Camilla Celani ${ }^{(\mathrm{c})}$, \\ Eleni Makrì ${ }^{(a)}$ and Franco Frati ${ }^{(d)}$ \\ (a) Pneumologia Riabilitativa, AO Istituti Clinici di Perfezionamento, Milan, Italy \\ (b) Allergologia, ASL di Frosinone, Frosinone, Italy \\ (c) Dipartimento di Pediatria, Sapienza Università di Roma, Rome, Italy \\ ${ }^{(d)}$ Dipartimento Medico-Scientifico, Stallergenes, Milan, Italy
}

\begin{abstract}
Objective. Allergic rhinitis (AR) is a disease with high and increasing prevalence. The management of AR includes allergen avoidance, anti-allergic drugs, and allergen specific immunotherapy (AIT), but only the latter works on the causes of allergy and, due to its mechanisms of action, modifies the natural history of the disease. Sublingual immunotherapy (SLIT) was proposed in the 1990s as an option to traditional, subcutaneous immunotherapy. Material and methods. We reviewed all the available controlled trials on the efficacy and safety of SLIT. Results and conclusion. Thus far, more than 60 trials, globally evaluated in 6 meta-analyses, showed that SLIT is an effective and safe treatment for AR. However, it must be noted that to expect clinical efficacy in the current practice SLIT has to be performed following the indications from controlled trials, that is, sufficiently high doses to be regularly administered for at least 3 consecutive years.
\end{abstract}

Key words: allergic rhinitis, sublingual immunotherapy, efficacy, safety, compliance, meta-analysis.

Riassunto (Il trattamento della rinite allergica con l'immunoterapia sublinguale: revisione della letteratura). Obiettivo. La rinite allergica è una malattia a prevalenza elevata e crescente. La gestione della rinite allergica consiste nell'allontanamento dell'allergene, nell'utilizzo di terapie anti-allergiche, e nell'immunoterapia specifica (AIT). Solo quest'ultima agisce sulle cause dell'allergia in quanto grazie al suo meccanismo d'azione modifica la storia naturale della malattia. L'immunoterapia sublinguale (SLIT) è stata proposta negli anni novanta come alternativa alla tradizionale immunoterapia sottocutanea. Materiali e metodi. Sono stati analizzati tutti gli studi controllati attualmente disponibili sull'efficacia e sulla sicurezza della SLIT. Risultati e conclusioni. Finora, più di 60 studi clinici controllati, analizzati globalmente in sei meta-analisi, hanno dimostrato la sicurezza e l'efficacia della SLIT nella terapia della rinite allergica. Tuttavia, per avere una buona risposta clinica, la SLIT deve essere eseguita seguendo le indicazioni degli studi controllati, che raccomandano l'utilizzo di dosi sufficientemente elevate per almeno tre anni consecutivi.

Parole chiave: rinite allergica, immunoterapia sublinguale, efficacia, sicurezza, compliance, meta-analisi.

\section{INTRODUCTION}

Epidemiologic data shows a high and increasing prevalence of allergic rhinitis (AR) worldwide [1]. AR is particularly frequent in children [2], in whom the atopic disease usually starts with atopic dermatitis and then develops into AR and asthma by the picture of the so-called "allergic march" [3].

AR is generally managed by allergen avoidance, which in reality is rarely feasible, drug treatment, which is mainly based on antihistamines and topical corticosteroids, and allergen-specific immunotherapy (AIT) [4]. AIT was introduced 100 years ago in the form of subcutaneous administration of gradually increasing doses of the specific causative allergen in order to decrease the clinical reactivity of allergic subjects [5]. The most important charac- teristic of AIT is the capacity to modify the natural course of the allergic disease, which ensures the persistence of its effectiveness even after the treatment is stopped, provided that sufficiently high doses are administered for an adequate period of time [4]. The availability of biologically potent allergen extracts in the 1980s disclosed the problem of the injective route, that is, the possible occurrence of adverse systemic reactions. Hence, when adequate measures are warranted, the safety profile of injective AIT is good [6]. However, if the reactions are of the anaphylactic type, they may be severe and, though very rarely, even fatal [7]. In 1987, the sublingual route was proposed for AIT [8], and in the ensuing years it emerged as the best option for immunotherapy, by demonstrating a comparable efficacy and better 
safety when compared to the classical subcutaneous route of administration [9].

Today, a high number of studies showing the efficacy of sublingual immunotherapy (SLIT) have made the use of this treatment more frequent than subcutaneous IT (SCIT) in several European countries, and recent studies are paving the way for the introduction of SLIT also in the USA [10, 11].

The goal of this review is to analyze up to date the role of SLIT in the treatment of AR through the evidence which demonstrates its efficacy and safety, while highlighting the pharmacoeconomic issue.

\section{EFFICACY OF SUBLINGUAL IMMUNOTHERAPY}

The clinical efficacy of SLIT in AR, similarly to AIT in general, is evaluated by the decrease in symptom scores of rhinitis and in the consumption of symptomatic anti-allergic drugs. Currently, more than 60 double-blind, placebo-controlled studies are available, and provided the material for numerous meta-analyses on SLIT.

The first meta-analysis was published in 2005, when 22 controlled trials were available, showing a significantly higher efficacy of SLIT versus placebo, with a standardized mean difference (SMD) corresponding to -0.42 for symptom scores $(p=0.002)$ and to -0.43 for medication scores ( $p=0.00003)$ [12]. In 2011, the same group updated the meta-analysis: 60 controlled trials were retrieved from the literature and 49 were suitable for pooling in meta-analysis. Hence, a significant reduction was found in symptoms (SMD - 0.49 , $\mathrm{p}<0.00001)$ and in medication use (SMD -0.32, $p$ $<0.00001)$ compared to the placebo. Therefore, the authors concluded that the updated review reinforced the statement of the previous meta-analysis that SLIT is effective for AR [13].

Other meta-analyses examined the results according to the type of patient or to the allergen used. Olaguibel et al. focused the interest on children and analyzed 7 controlled studies; the results showed that SLIT was significantly effective on asthma symptoms (SMD -1.42) and on drug consumption (SMD -1.01), but no significant improvement was found with respect to nasal and eye symptoms [14]. However, a subsequent meta-analysis on SLIT in children, concerning only the efficacy on AR, showed positive outcomes, with a significant reduction of symptoms $(\mathrm{SMD}-0.56, \mathrm{p}=0.02)$ and medication scores (SMD $-0.76, \mathrm{p}=0.03)[15]$.

Concerning the allergen used, Compalati et al. considered 8 controlled studies for house dust mite-induced AR, including 194 adults and children, and found a significant reduction in symptoms of AR (SMD -0.95; p = 0.02) and in antiallergic medication use (SMD -1.88; $\mathrm{p}=0.04$ ) in SLIT treated patients when compared to the placebo [16]. Furthermore, Di Bona et al. analyzed the randomized controlled studies performed with grass pollen extracts: a significant decrease of both symptoms (SMD -0.32) and medication use (SMD -0.33) was found for SLIT when compared to placebo. Of note, when using an amount of $275 \mathrm{mcg} /$ month of major allergen as a cut-off separating low doses from high doses, the clinical benefit was much better (SMD -0.47) in patients receiving higher doses as compared to those receiving low doses (SMD -0.16). Other observations concerned higher efficacy in adults rather than children, and when preseasonal treatment was continued for more than 12 weeks [17]. The main features of the meta-analyses on SLIT are summarized in Table 1.

It must be noted that meta-analysis is not the perfect method, for it is affected by the problem of the heterogeneity of the included studies, due to the different dosages, standardization methods, treatment schedules, and patient populations. When the metaanalyses are dissected, it is possible to draw different conclusions. In fact, Nieto et al. concluded that the meta-analyses show "discrepancies, inconsistencies, and lack of robustness and do not provide enough evidence" for the current routine use of SLIT [18]. Conversely, the overall evaluation of all meta-analyses ( 5 on SLIT and 2 on SCIT) by Compalati et al, in spite of a significant heterogeneity of studies and one negative analysis, allowed the authors to conclude that "AIT can be recommended for the treatment of respiratory allergy because of its efficacy in reducing asthma and rhinitis symptoms" [19].

A possible solution to the problem of heterogeneity is offered by single studies conducted on large num-

Table 1 | Results from meta-analyses on SLIT in allergic rhinitis

\begin{tabular}{|c|c|c|c|c|}
\hline Author (year) & Population & Number of patients & Allergen used & SMD* \\
\hline Wilson et al. (2005) [12] & Adults and children & 979 (503 active, 476 placebo) & Various & -0.42 \\
\hline Olaguibel et al. (2005) [14] & Children & 256 (129 active, 127 placebo) & Various & -0.44 \\
\hline Penagos et al. (2006) [15] & Children & 484 (245 active, 239 placebo) & Various & -0.56 \\
\hline Compalati et al. (2009) [16] & Adults and children & 382 (194 active, 188 placebo) & House dust mite & -0.95 \\
\hline Di Bona et al. (2010) [17] & Adults and children & 2971 (1518 active, 1453 placebo) & Grass pollen & -0.32 \\
\hline Radulovic et al. (2011) [13] & Adults and children & 4589 (2333 active, 2256 placebo) & Various & -0.49 \\
\hline
\end{tabular}


bers of patients that allow adequate statistical power. The development of SLIT preparations has led to the introduction of grass pollen tablets, that were evaluated on large populations of patients, namely 855 adults treated by a Timothy grass extract [20], 628 adults treated by a 5-grass pollen extract [21], and 278 children treated by the same 5 -grass preparation [22]. The results of these studies confirmed that SLIT induces a highly significant improvement during the grass pollen season in symptoms and medications scores in actively treated patients when compared to the placebo-treated patients. In addition, valuable observations on the dose dependence of clinical efficacy were done: only high doses, corresponding to 75000 standard quality (SQ) units in the trial with the Timothy grass pollen [19] and to 300 Index of reactivity (IR) units in the trial with the 5-grass extract [20] were efficacious. Such doses are equivalent to 15 mcg and $20 \mathrm{mcg}$ of the major grass allergen Phl p 5 , respectively. Based on this information, the World Allergy Organization Position Paper on SLIT suggested as optimal a monthly cumulative dose of 600 mcg of the major allergen Phl p 5 [23].

Furthermore, a central issue of SLIT efficacy is the identification of patients who are more prone to respond to the treatment. By a post-hoc analysis of data from the studies performed for the registration of the new grass pollen tablets for SLIT cited above [21, 22], the magnitude of efficacy was found to be higher in patients with more severe symptoms during the pollen season. In particular, in the study on adults the differences of the symptom-medication score in the active versus placebo were $15 \%, 26 \%$, and $37 \%$ for the low, moderate and high severity tertiles, respectively. In the study on children, these values corresponded to $10 \%, 33 \%$ and $34 \%$, respectively [24].

As noted above, the major advantage of AIT over drug treatment is that the efficacy on allergic symptoms persists after its discontinuation [5]. This was recently demonstrated also concerning SLIT. In a study on SLIT performed by a dust mite extract, 137 patients were divided in 2 groups, 67 receiving the treatment for 2 years and 70 receiving the treatment for 3 years; all patients were followed-up for 3 years after stopping SLIT, and a greater improvement of symptoms was found in patients treated for 3 years [25]. In a prospective open controlled study, patients monosensitized to mites were divided in 4 groups, 1 receiving only drug treatment and the other 3 receiving SLIT for 3, 4, or 5 years. The observation period was extended to 15 years, and the clinical scores showed that the clinical benefit continued for 7 years in patients treated for 3 years, while it continued for 8 years in those treated for $4-5$ years [26].

\section{SAFETY AND TOLERABILITY OF SUBLINGUAL IMMUNOTHERAPY}

The first observations on safety and tolerability of SLIT were reported in the meta-analyses on efficacy, and showed that the most common adverse events were local reactions in the mouth followed by gastrointestinal reactions (including vomiting and diarrhea), that systemic reactions such as asthma, rhinitis, or urticaria were quite rare, and that no anaphylactic reaction was described in controlled trials [12-15].

However, reviews specifically addressing SLIT safety are also available, concerning only children [27, 28] or patients of any age $[29,30]$. Of interest, differently from SCIT, a dose-dependence of safety was not apparent, since the rate of systemic reactions was comparable in studies using low doses and in studies using high doses [29]. The local reactions are generally estimated to affect $20-40 \%$ of patients, but they can be easily managed and generally do not require to withdraw the treatment [31]. Still, single reports of anaphylactic reactions are available. In most cases, the reaction was associated with mistakes, such as the use of incorrect mix of allergens or the consumption of very high allergen doses [32]. Notwithstanding, an increased risk is apparent in subjects undergoing SLIT because of previous systemic reactions to SCIT [33,34], in particular when no updosing regimens are used, and this warrants reconsideration of systemic reactions to SCIT as an admission criteria to SLIT [35]. Indeed, starting the SLIT treatment with the maintenance dose is generally not recommended, regardless of previous reactions to SCIT, because a phase 1 study comparing different doses and different regimens showed that only the group of patients treated with the highest dose with no updosing had severe local reactions, including swelling of the throat [36].

\section{PHARMACOECONOMIC ASPECTS}

The significant reduction in the use of symptomatic drugs showed by all meta-analyses on SLIT highlights the cost-effectiveness of this treatment. In fact, a number of studies addressed the pharmacoeconomics of AIT. The review of such studies in 2008 led to the conclusion that there was clear data that substantiated the capacity of both SCIT and SLIT to be very beneficial to the healthcare system. The major advantage of AIT takes place when the treatment, usually after 3 years, is stopped, because the effectiveness of AIT persists over time [37]. Such persistence is related to the immunologic changes induced by AIT, especially regarding the $\mathrm{T}$ lymphocytes and their cytokine profile and the production of IgG blocking antibodies [38] and the consequent modification of the natural history of respiratory allergy [39]. Recent studies expanded the concept of economic advantage of AIT even before its termination. In a study performed in US, children with AR treated with AIT had significantly lower 18-month median total health care costs (\$ 3247 vs \$ 4872), outpatients costs of AIT-related care (\$1107 vs $\$ 2626)$, and pharmacy costs $(\$ 1108$ vs \$1316) compared with matched controls $(\mathrm{p}<0.001$ for all comparisons). This data has led the authors to conclude that "This study demonstrates the potential 
for early and significant cost savings in children with AR treated with immunotherapy. Greater use of this treatment in children could significantly reduce ARrelated morbidity and its economic burden" [40]. Of interest, the direct comparison of costs between SCIT and SLIT was in favour of the latter, as expected because of the lack of the necessity for hospital visits for the injections. In France, the reported savings compared with drug treatment over a 6-year period were $€ 393$ for dust mite and $€ 1327$ for pollen allergy with SCIT, but they were $€ 3158$ for dust mite and $€ 1708$ for pollen allergy with SLIT [41]. In the Czech Republic, the sum of direct and indirect costs recorded, over a 3-year treatment, $€ 684$ for SLIT and $€ 1004$ for SCIT [42].

\section{CONCLUDING REMARKS}

SLIT has achieved sound evidence of efficacy and safety and currently in some European countries is more frequently used than the classical SCIT, due to better safety. Other advantages over SCIT concern the cost [37] as well as the compliance [43], because SLIT does not need to be administered in a medical setting. Still, it is important to note that such outcomes take place only if SLIT meets its needs, that is, the administration of high doses is continued on a regular basis for at least 3 consecutive years. In fact, SLIT efficacy is dose-dependent and a sufficient duration is crucial to elicit the immunologic changes underlying its clinical effectiveness.

\section{Conflict of interest statement}

Cristoforo Incorvaia is a scientific consultant for Stallergenes Italy. Franco Frati is the Medical Director of Stallergenes Italy. Alessia Di Rienzo, Camilla Celani and Eleni Makrì have no competing interest.

Received on 2 February 2012.

Accepted on 2 April 2012.

\section{References}

1. Asher MI, Montefort S, Bjorksten B, et al. ISAAC Phase Three Study Group: Worldwide time trends in the prevalence of symptoms of asthma, allergic rhinoconjunctivitis, and eczema in childhood: ISAAC Phases One and Three repeat multicountry cross-sectional surveys. Lancet 2006;368:733-43. http://dx.doi.org/10.1016/S0140-6736(06)69283-0

2. Balatsouras DG, Koukoutsis G, Ganelis P, et al. Study of allergic rhinitis in childhood. Int J Otolaryngol, in press, 2011. http://dx.doi.org/10.1155/2011/487532

3. Spergel JM, Paller AS. Atopic dermatitis and the atopic march. J Allergy Clin Immunol 2003;112(Suppl. 6):S118-27. http://dx.doi.org/10.1016/j.jaci.2003.09.033

4. Bousquet J, Lockey R, Malling HJ (eds.). Allergen immunotherapy: therapeutic vaccines for allergic diseases. A WHO position paper. J Allergy Clin Immunol 1998;102:58-62. http://dx.doi.org/10.1016/S0091-6749(98)70271-4

5. Incorvaia C, Frati F. One century of allergen-specific immunotherapy for respiratory allergy. Immunotherapy 2011;3:629-35. http://dx.doi.org/10.2217/imt.11.36

6. Schiappoli M, Ridolo E, Senna G, et al. A prospective Italian survey on the safety of subcutaneous immunotherapy for respiratory allergy. Clin Exp Allergy 2009;39(10):1569-74. http://dx.doi.org/10.1111/j.1365-2222.2009.03286.x

7. Lockey RF, Benedikt LM, Turkeltaub PC, et al. Fatalities from immunotherapy (IT) and skin testing (ST). J Allergy Clin Immunol 1987;79:660-77. http://dx.doi.org/10.1016/S0091-6749(87)80164-1

8. Scadding GK, Brostoff J. Low dose sublingual therapy in patients with allergic rhinitis due to house dust mite. Clin Allergy 1986:16:483-91.

http://dx.doi.org/10.1111/j.1365-2222.1986.tb01983.x

9. Canonica GW, Passalacqua G. Noninjection routes for immunotherapy. J Allergy Clin Immunol 2003;111:437-48. http://dx.doi.org/10.1067/mai.2003.129

10. Bush RK, Swenson C, Fahlberg B, et al. House dust mite sublingual immunotherapy: results of a US trial. J Allergy Clin Immunol 2011;127:984-1. http://dx.doi.org/10.1016/j.jaci.2010.11.045

11. Cox L, Wallace D. Specific allergy immunotherapy for allergic rhinitis: subcutaneous and sublingual. Immunol Allergy Clin of North Am 2011;31:561-99. http://dx.doi.org/10.1016/j.iac.2011.05.001

12. Wilson DR, Torres-Lima M, Durham S. Sublingual immunotherapy for allergic rhinitis: systematic review and metaanalysis. Allergy 2005;60:4-12. http://dx.doi.org/10.1111/j.1398-9995.2005.00699.x

13. Radulovic S, Wilson D, Calderon M, Durham S. Systematic reviews of sublingual immunotherapy. Allergy 2011;66:740-52. http://dx.doi.org/10.1111/j.1398-9995.2011.02583.x

14. Olaguibel JM, Alvarez Puebla MJ. Efficacy of sublingual allergen vaccination for respiratory allergy in children. Conclusions from one meta-analysis. J Investig Allergol Clin Immunol 2005; 15:9-16.

15. Penagos M, Compalati E, Tarantini F, et al. Efficacy of sublingual immunotherapy in the treatment of allergic rhinitis in pediatric patients 3-18 years of age: a meta analysis of randomized placebo-controlled, double blind trials. Ann Allergy Asthma Immunol 2006;97:141-8. http://dx.doi.org/10.1016/S1081-1206(10)60004-X

16. Compalati E, Passalacqua G, Bonini M, Canonica GW. The efficacy of sublingual immunotherapy for house dust mites respiratory allergy: results of a GA2LEN meta-analysis. Allergy 2009;64:1570-9.

http://dx.doi.org/10.1111/j.1398-9995.2009.02129.x

17. Di Bona D, Plaia A, Scafidi V, et al. Efficacy of sublingual immunotherapy with grass allergens for seasonal allergic rhinitis: a systematic review and meta-analysis. J Allergy Clin Immunol 2010;126:558-66. http://dx.doi.org/10.1016/j.jaci.2010.06.013

18. Nieto A, Mazon A, Pamies R, et al. Sublingual immunotherapy for allergic respira. tory diseases: an evaluation of meta-analyses. J Allergy Clin Immunol 2009;124:157-61. http://dx.doi.org/10.1016/j.jaci.2009.04.015

19. Compalati E, Penagos M, Tarantini F, et al. Specific immunotherapy for respiratory allergy: state of the art according to current meta-analyses. Ann Allergy Asthma Immunol 2009; $102: 22-8$. http://dx.doi.org/10.1016/S1081-1206(10)60103-2

20. Durham SR, Yang WH, Pedersen MR, et al. Sublingual immunotherapy with once daily grass allergen tablet: a randomized controlled trial in seasonal allergic rhinoconjunctivitis. J Allergy Clin Immunol 2006;117:802-9. http://dx.doi.org/10.1016/j.jaci.2005.12.1358

21. Didier A, Malling HJ, Worm M, et al. Optimal dose, effica- 
cy, and safety of once daily sublingual immunotherapy with a 5 -grass pollen tablet for seasonal allergic rhinitis. J Allergy Clin Immunol 2007;120:1338-45.

http://dx.doi.org/10.1016/j.jaci.2007.07.046

22. Wahn U, Tabar A, Kuna P, et al. SLIT Study Group: Efficacy and safety of 5-grass pollen sublingual immunotherapy tablets in pediatric allergic rhinoconjunctivitis. J Allergy Clin Immunol 2009;123:160-6.

http://dx.doi.org/10.1016/j.jaci.2008.10.009

23. Canonica GW, Bousquet J, Casale T, et al. Sublingual immunotherapy: World Allergy Organization Position Paper 2009, Allergy 2009;64(Suppl. 91):1-59.

24. Devillier P, Brehler R, Sastre J, et al. The clinical development of specific immunotherapies: specific methodological issues and clinical interpretation of results. Allergy 2010;65(Suppl. 92):567-8.

25. Tahamiler R, Saritzali G, Canakcioglu S. Long-term efficacy of sublingual immunotherapy in patients with perennial rhinitis. Laryngoscope 2007;117:965-9. http://dx.doi.org/10.1097/MLG.0b013e31804f8141

26. Marogna M, Spadolini I, Massolo A, et al. Long-lasting effects of sublingual immunotherapy accordino to its duration: a 15-year prospective study. J Allergy Clin Immunol 2010;126: 969-75. http://dx.doi.org/10.1016/j.jaci.2010.08.030

27. Andrè $C$, Vatrinet $C$, Galvain S. Safety of sublingual swallow immunotherapy in children and adults. Int Arch Allergy Immunol 2000;121:220-34.

28. Di Rienzo V, Minelli M, Musarra A, et al. Post-marketing survey on the safety of sublingual immunotherapy in children below the age of 5 years. Clin Exp Allergy 2005;35:560-4. http://dx.doi.org/10.1111/j.1365-2222.2005.02219.x

29. Gidaro GB, Marcucci F, Sensi L, et al. The safety of sublingual-swallow immunotherapy: an analysis of published studies. Clin Exp Allergy 2005;35:565-71. http://dx.doi.org/10.1111/j.1365-2222.2005.02240.x

30. Passalacqua G, Guerra L, Compalati E, et al. The safety of allergen specific sublingual immunotherapy. Curr Drug Saf 2007;2:117-23. http://dx.doi.org/10.2174/157488607780598340

31. Frati F, Sensi L, Di Rienzo V, et al. A model for management of sublingual immunotherapy. Eur Ann Allergy Clin Immunol 2003;35:56-60.

32. André C, Fadel R. Anaphylaxis caused by allergen sublingual immunotherapy? Allergy 2007;62:1220-1. http://dx.doi.org/10.1111/j.1398-9995.2007.01512.x
33. de Groot H, Bijl A. Anaphylactic reaction after the first dose of sublingual immunotherapy with grass pollen tablet. Allergy 2009:64:963-4. http://dx.doi.org/10.1111/j.1398-9995.2009.01998.x

34. Cochard MM, Eigenmann PA. Sublingual immunotherapy is not always a safe alternative to subcutaneous immunotherapy. J Allergy Clin Immunol 2009;124:378-9. http://dx.doi.org/10.1016/j.jaci.2009.04.040

35. Incorvaia $\mathrm{C}$, Mauro M. Do indications to sublingual immunotherapy need to be revised? J Allergy Clin Immunol 2010; 125:277-8.

http://dx.doi.org/10.1016/j.jaci.2009.10.033

36. Larsen TH, Poulsen LK, Melac M, et al. Safety and tolerability of grass pollen tablets in sublingual immunotherapy - a phase 1 study. Allergy 2006;61:1173-6. http://dx.doi.org/10.1111/j.1398-9995.2006.01203.x

37. Berto P, Frati F, Incorvaia C. Economic studies of immunotherapy: a review. Curr Opin Allergy Clin Immunol 2008;8:585-9. http://dx.doi.org/10.1097/ACI.0b013e32831411e9

38. Ciprandi G, Tosca MA, Marseglia GL. Sublingual immunotherapy mechanisms of action: the role of Th1 response. Int J Immunopathol Pharmacol 2009;22(Suppl. 4):9-12.

39. Durham SR, Emminger W, Kapp A, et al. Long-term clinical efficacy in grass-pollen induced rhinoconjunctivitis after treatment with SQ-standardized grass allergy immunotherapy tablet. J Allergy Clin Immunol 2010;125:131-8. http://dx.doi.org/10.1016/j.jaci.2009.10.035

40. Hankin CS, Cox L, Lang D, et al. Allergen immunotherapy and health care cost benefits for children with allergic rhinitis: a large-scale, retrospective, matched cohort study. $J$ Allergy Clin Immunol 2010;104:79-85. http://dx.doi.org/10.1016/j.anai.2009.11.010

41. Omnes LF, Bousquet J, Scheinmann P, et al. Pharmacoeconomic assessment of specific immunotherapy versus current symptomatic treatment for allergic rhinitis and asthma in France. Eur Ann Allergy Clin Immunol 2007;39:148-56.

42. Podladnikova J, Krcmova I, Vlcek J. Economic evaluation of sublingual vs subcutaneous allergen immunotherapy. Ann Allergy Asthma Immunol 2008;100:482-9. http://dx.doi.org/10.1016/S1081-1206(10)60475-9

43. Incorvaia C, Mauro M, Ridolo E, et al. Patient's compliance with allergen immunotherapy. Patient Prefer Adherence 2008;2:247-51.

http://dx.doi.org/10.2147/PPA.S3806 